\title{
Erratum to: Sunlight and dietary contributions to the seasonal vitamin D status of cohorts of healthy postmenopausal women living at northerly latitudes: a major cause for concern?
}

H. M. Macdonald • A. Mavroeidi • W. D. Fraser •

A. L. Darling • A. J. Black • L. Aucott • F. O'Neill •

K. Hart • J. L. Berry • S. A. Lanham-New • D. M. Reid

Published online: 26 January 2011

(C) International Osteoporosis Foundation and National Osteoporosis Foundation 2011

\section{Erratum to: Osteoporos Int} DOI 10.1007/s00198-010-1467-x

The key in the legend below Fig. 3 incorrectly identified the black and white bars. The authors apologise for this error and are pleased to present the figure and corrected legend here.

The online version of the original article can be found at http://dx.doi. org/10.1007/s00198-010-1467-x

H. M. Macdonald · A. Mavroeidi • A. J. Black · L. Aucott •

J. L. Berry

F. O’Neill • D. M. Reid

University of Aberdeen,

Foresthill,

Aberdeen AB25 2ZD, UK

Vitamin D Research Group, Department of Medicine,

Manchester Royal Infirmary,

Oxford Road,

Manchester M13 9WL, UK

W. D. Fraser

Department of Musculoskeletal Biology, University of Liverpool,

Liverpool L69 3GA, UK

\section{A. L. Darling $\cdot$ K. Hart $\cdot$ S. A. Lanham-New}

Nutritional Sciences Division, Faculty of Health and Medical

Sciences, University of Surrey,

Guildford,

Surrey GU2 7XH, UK
H. M. Macdonald $(\square)$

Musculoskeletal Research, Health Sciences Building,

University of Aberdeen,

Foresthill,

Aberdeen AB25 2ZD, UK

e-mail: h.macdonald@abdn.ac.uk 

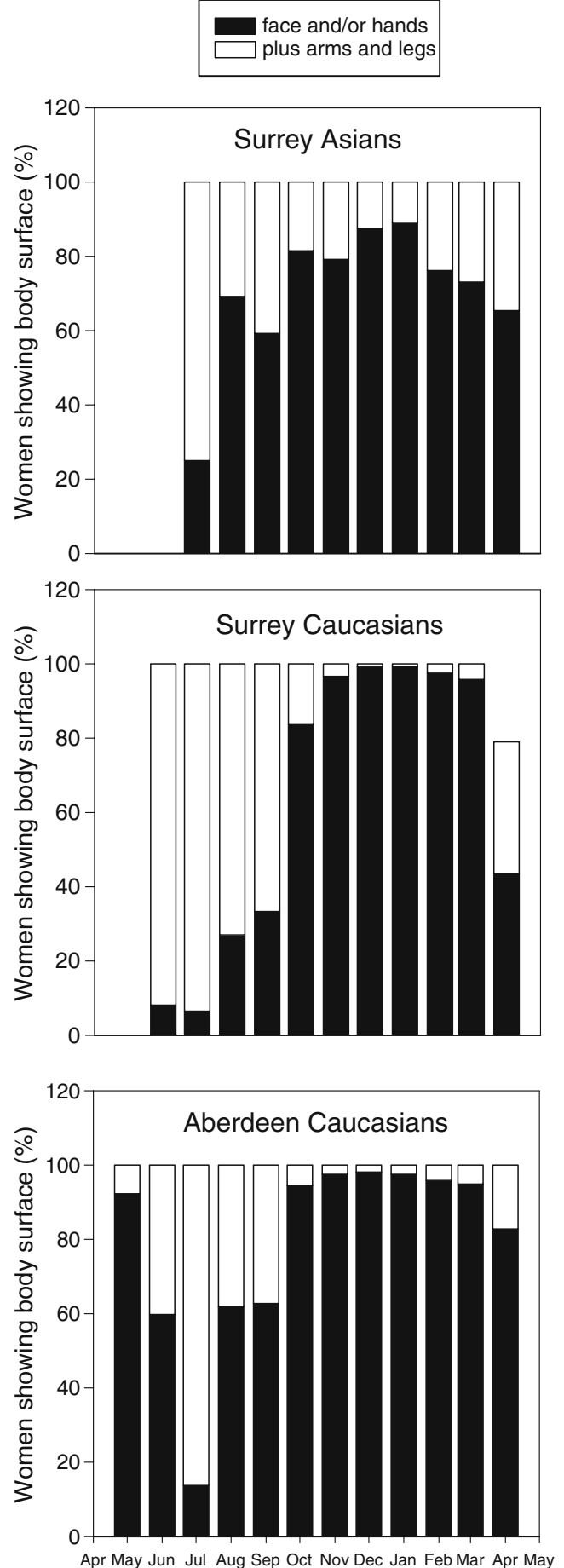

Fig. 3 Seasonal changes in the number of women showing face and/ or hands only, or having arms or legs uncovered, from May 2006 to April 2007 (black bars: face or hands and face; white bars: plus arms or legs). Due to the timing of recruitment in Surrey, May 2006 is missing for the Caucasians and May and June 2006 for the Asians 